\title{
Longitudinal study of adolescent tobacco use and tobacco control policies in India
}

\author{
Ritesh Mistry ${ }^{1 *}$ (D), Mangesh S. Pednekar ${ }^{2}$, Prakash C. Gupta ${ }^{2}$, Trivellore E. Raghunathan ${ }^{3,4}$, Surekha Appikatla ${ }^{1}$, \\ Namrata Puntambekar ${ }^{2}$, Keyuri Adhikari $^{2}$, Maqsood Siddiqi ${ }^{5}$ and William J. McCarthy ${ }^{6}$
}

\begin{abstract}
Background: This project will use a multilevel longitudinal cohort study design to assess whether changes in Community Tobacco Environmental (CTE) factors, measured as community compliance with tobacco control policies and community density of tobacco vendors and tobacco advertisements, are associated with adolescent tobacco use in urban India. India's tobacco control policies regulate secondhand smoke exposure, access to tobacco products and exposure to tobacco marketing. Research data about the association between community level compliance with tobacco control policies and youth tobacco use are largely unavailable, and are needed to inform policy enforcement, implementation and development.

Methods: The geographic scope will include Mumbai and Kolkata, India. The study protocol calls for an annual comprehensive longitudinal population-based tobacco use risk and protective factors survey in a cohort of 1820 adolescents ages 12-14 years (and their parent) from baseline (Wave 1) to 36-month follow-up (Wave 4). Geographic Information Systems data collection will be used to map tobacco vendors, tobacco advertisements, availability of e-cigarettes, COTPA defined public places, and compliance with tobacco sale, point-of-sale and smoke-free laws. Finally, we will estimate the longitudinal associations between CTE factors and adolescent tobacco use, and assess whether the associations are moderated by family level factors, and mediated by individual level factors.

Discussion: India experiences a high burden of disease and mortality from tobacco use. To address this burden, significant long-term prevention and control activities need to include the joint impact of policy, community and family factors on adolescent tobacco use onset. The findings from this study can be used to guide the development and implementation of future tobacco control policy designed to minimize adolescent tobacco use.
\end{abstract}

Keywords: Tobacco, Adolescents, Policy, Compliance

\section{Background}

Tobacco use prevention and control are public health priorities globally and in India. The prevalence of adult current tobacco use in India is $42 \%$ for males and $14 \%$ for females [1], and adolescent current tobacco use prevalence is $19 \%$ for males and $8 \%$ for females [2]. Annually, nearly 1.3 million people die in India from a tobacco-related disease [3, 4]. Although tobacco control policies are important strategies to reduce population level tobacco use, the extent and role of partial compliance are not well understood [5, 6]. A key set of India's

\footnotetext{
* Correspondence: riteshm@umich.edu

'Department of Health Behavior and Health Education, University of Michigan School of Public Health, 1415 Washington Heights, SPH I, Room 3806, Ann Arbor, Ml 48109-2029, USA

Full list of author information is available at the end of the article
}

tobacco control policies pertain to Articles 8, 13 and 16 of the FCTC (WHO Framework Convention for Tobacco Control) regarding secondhand smoke exposure, access to tobacco products and tobacco promotion, respectively. Major provisions of national and local laws regulate where tobacco can be used, sold and advertised (e.g., Sections 4-7 of the Cigarettes and Other Tobacco Products Act or COTPA). Reports from several urban areas in India suggest that compliance was consistently low for restrictions on tobacco advertisements at the point-of-sale $[6,7]$, and was moderate for bans on the sale and marketing of tobacco near schools in Mumbai [8] and Ahmedabad [9], high for smoke-free laws in one district in Punjab [10], and high for the ban on the sale of gutkha (a flavored smokeless tobacco product) [11, 12]. The study described in this paper will gather and 
analyze population-based, prospective data on compliance with existing tobacco control laws in Mumbai and Kolkata, India. The primary aim is to assess how variations in compliance with tobacco point-of-sale and smoke-free laws are associated with tobacco use in adolescents.

\section{Community tobacco environment}

We define the Community Tobacco Environment (CTE) as places within community neighborhoods where tobacco products are sold, advertised and used, and level of compliance with existing point-of-sale and smoke free laws. Observational studies suggest that reducing the number of places where tobacco products are sold [1317] and advertised, especially near schools, may be effective in reducing youth tobacco use $[18,19]$, including in India $[8,20-22]$. With some exceptions $[15,19]$, past studies were limited to using cross-sectional data and indirect environmental measures, e.g., self-reports about community exposures to tobacco advertisements [20]. The retailer point-of-sale (POS) environment is being increasingly recognized as an important setting in which policies may be used to reduce the purchase and consumption of tobacco and other health damaging products by adolescents [23]. Exposure to tobacco advertisements and products at the point-of-sale has been linked to adolescent tobacco use [19], increased brand recognition in students [24], impulse purchases of tobacco in smokers [25], and exposures are concentrated in low-income neighborhoods [26]. Laws that ban smoking in public places are associated with lower smoking in youth $[27,28]$.

\section{Family influences}

The influence of the CTE on adolescent tobacco use may be moderated by family contexts. The family environment has important influences on adolescent development and resiliency factors $[29,30]$ that can mitigate against risks in the environment. For example, demanding and responsive parenting styles have been shown to bolster adolescent resiliency [31], and reduce adolescent health risk behaviors [32, 33], including tobacco use [33-35]. Though research from India identifies risks associated with tobacco use by family members [36], to our knowledge there is a dearth of published research on how parenting styles and practices in India may be associated with adolescent tobacco use, and how parenting interacts with environmental influences.

\section{Individual level factors}

Individual level factors may partially mediate the relation between CTE factors and adolescent tobacco use. For instance, perceived ease of access to tobacco [37], perceived norms about tobacco use [38], and perceived exposure to tobacco advertisements in the community have been linked to youth tobacco use. These factors may help explain associations between adolescent tobacco use and CTE factors. High youth receptivity to tobacco-promoting messages and exposure to advertisements is an ongoing challenge for tobacco control because they have been shown to increase risk of youth tobacco use in India [20].

\section{Conceptual framework}

Multilevel approaches that incorporate community, family and individual level factors can provide a richer understanding of the impact of tobacco control policies on adolescent tobacco use [39-41]. With some exceptions $[40,42]$, research has primarily focused on individual and family environmental factors, or individual and community environmental factors, but more research is needed that include the contribution of community, family and individual level factors simultaneously when assessing the multilevel determinants of adolescent tobacco use behaviors [43, 44].

Our multilevel framework is guided by a socioecological perspective [45] that draws from Social Cognitive Theory [46], the Theory of Triadic Influences [47] and resiliency theory [31, 48]. Social Cognitive Theory posits reciprocal causation between health behaviors, cognition/affect and environmental factors. Theory of Triadic Influences states that behaviors are determined by broader social economic factors, immediate social contexts (e.g. family), and individual characteristics. Resiliency theory provides a positive youth development perspective that focuses on internal and external assets (mental health, family support, good parenting, peers who don't use) that mitigate the effect of risk factors. The framework includes community context (e.g. CTE factors), the immediate social context (i.e., family context and peer influences), and individual level factors such as knowledge, perceptions and affect. Figure 1 shows the hypothesized associations between the CTE factors and adolescent tobacco use (arrow a). Factors measuring adolescent access to tobacco products are hypothesized partial mediators (arrows b and c). Family factors are hypothesized moderators (arrow d) that protect against or enhance community level effects (arrow e). For example, parent support may buffer the effect of high tobacco vendor density on adolescent tobacco use, and parent tobacco use may exacerbate this effect.

\section{Research questions}

The project will address the following research questions and hypotheses:

a. What is the association between adolescent tobacco use initiation and compliance with tobacco control 


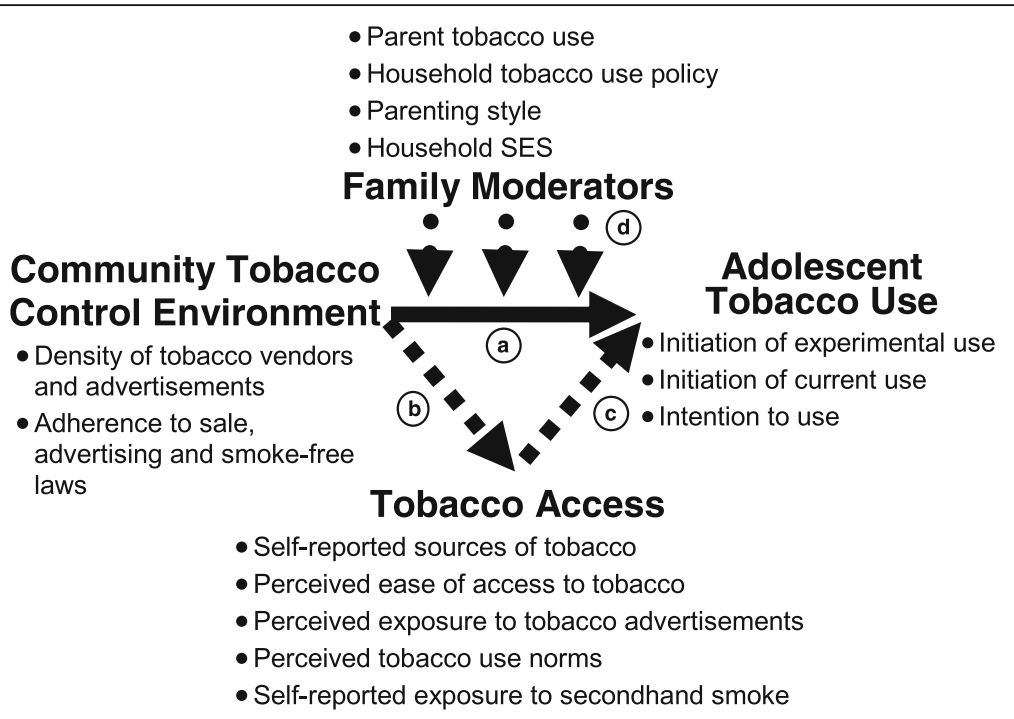

Fig. 1 Conceptual Framework

laws about tobacco sales to minors, advertisements and smoking in public places? Hypothesis:

Adolescent tobacco use initiation will be negatively associated with community compliance with COTPA tobacco control laws.

b. What is the association between adolescent tobacco use initiation and the density of tobacco vendors and tobacco advertisements? Hypothesis: Adolescent tobacco use initiation will be positively associated with greater density of tobacco vendors and tobacco advertisements.

c. Does adolescent perceived access to tobacco products and perceived norms about tobacco use partially mediate the association between CTE factors and adolescent tobacco use initiation? Hypothesis: Compared to non-users, adolescents who initiate tobacco use over the follow-up period will be more likely to report easier access to tobacco products and greater perceived prevalence of tobacco use, thus explaining some of the observed association of adolescent tobacco use initiation with variation in CTE factors.

d. How do family factors modify the effect of CTE factors and adolescent tobacco use? Hypothesis: Parenting style, family conflict, parent tobacco use and household tobacco use policy will moderate the relationship between CTE factors and tobacco use initiation.

\section{Methods}

We will conduct a comprehensive longitudinal population-based household survey of 1820 adolescents 12-14 years of age and their parent/main caregiver, with data collection occurring at baseline (Wave 1), 12-month (Wave 2), 24-month (Wave 3) and 36-month follow-ups (Wave 4). The project will be conducted in Mumbai and Kolkata, India; two large, populous, geographically dispersed urban areas that reflect India's urban variation in the prevalence of tobacco use, tobacco control policy implementation, socioeconomic development, infrastructure and cultural factors.

\section{Sampling plan}

A multi-stage sampling design will be used to obtain a representative sample of communities and adolescents in both cities. We will use a comprehensive sampling frame from the National Sample Survey Organization (NSSO) of the Ministry of Statistics and Programme Implementation called the Urban Frame Survey [49], which covers all populated urban areas within the country. The geographies of the sampling frame are hierarchically nested: States, Cities, Investigator Units (IV units) and Blocks. We will select Mumbai, Maharashtra and Kolkata, West Bengal for our sampling frame and include Blocks designated by the NSSO as Affluent Areas, Residential Areas and Slum Areas [49]. These areas represent $97 \%$ of all Blocks in both cities. We will sample 11 IV units per city and then 4 Blocks on average per IV unit for a total of 88 Blocks ( 2 cities $\times 11$ IV Units $\times 4$ Blocks per IV unit). All eligible households within sampled Blocks will be approached for enrollment in the study. If the target sample size is not achieved from the 88 sampled Blocks, additional blocks will be sampled as needed. Eligible households will be defined as those having at least one adolescent aged 12-14 years living with his/her primary adult caregiver. Adolescent sampling weights will be developed using base weights proportional to the reciprocal of the product of the selection 
probabilities at each stage with adjustment for unit non-response.

\section{Data collection activities Household component}

Household data collection will include interviewer-administered adolescent and parent/primary caregiver surveys. The adolescent survey will be adapted from our past research [6, 8, 14, 50-52], and guided by our conceptual framework and the literature on the most important risk and protective factors for tobacco use. It will include items found in the Global Youth Tobacco Survey-India [2], Mumbai Student Tobacco Survey [6, 8], and the Tobacco Control Policy - India survey, an adaptation of the International Tobacco Control Policy Evaluation Project Survey [53]. We will emphasize policy components such as bans on the sale of gutkha, smoke-free policies, and policies restricting tobacco advertisements. We will also include items about interactions with tobacco retail environments in home and school neighborhoods as well as COTPA defined public places. The survey will include measures of smoking and smokeless tobacco use (including gutkha, hookah and e-cigarettes), tobacco use risk factors and family factors. The parent survey will be guided by the Global Adult Tobacco Survey [54] and the literature about family risk and protective factors for adolescent tobacco use. The survey interviews will be conducted English, Hindi, Marathi and Bengali by trained field investigators using a computer-aided personal interviewing system.

\section{Community component}

We will measure CTE factors by collecting GIS data about all tobacco vendors and tobacco advertisements in the 22 sampled IV units. We will conduct audits of all tobacco POS environments and COTPA defined public places to measure compliance with POS and smoke-free laws. Baseline GIS data will be collected during Wave 1, and will be updated at Wave 4 .

Mapping In each community, all tobacco-related community features will be mapped. A "community" will be defined as the IV unit in which the sampled household is located. GPS enabled tablet computers will be used to geocode locations of all tobacco vendors, tobacco advertisements, COTPA defined public places (hospital buildings; restaurants; public offices; court buildings, educational institutions; bus stops). The mapping activities will be conducted by field teams trained to use the field GIS mapping equipment and procedures. Detailed mapping and training protocols will be adapted from our previous experience $[8]$ and the literature $[55,56]$.
Tobacco POS audits All tobacco vendors will be audited for compliance to POS laws. We will adapt from our previous experience [6] and the existing literature [57]. The audits will focus on compliance with tobacco POS provisions. POS audits that we used previously [6] had compliance items with good internal consistency $(\alpha=0.78)$, face validity and construct validity. Compliance will be measured (Yes $=1 ; \mathrm{No}=0$ ) for each POS provision (Table 1), and summed to create a POS Compliance Score. In a sample of mapped tobacco vendors, we will measure compliance with the ban on tobacco sales to minors by using trained actors who look like minors. Successful purchase attempts will be recorded (Succeed $=1$; Not succeed $=0$ ). The procedures will be guided by the literature on conducting compliance checks to tobacco sale to minors [58-60].

Public place audits All COTPA defined public places will be audited for compliance with smoke-free laws. We will adapt existing methods [61], and those recommended by researchers in India [62, 63]. Presence/absence (Yes $=1 ; \mathrm{No}=0)$ of items in Table 2 will be noted, and observations will be summed to create a Smoke-free Compliance Score.

\section{Measures}

Primary outcomes The primary outcomes will be initiation of experimental tobacco use and initiation of current tobacco use between Wave 1 (baseline) and Wave 4 surveys using existing methods [64, 65], and adapting them for smoking and smokeless tobacco products in India. Initiation of experimental use at follow-up will be measured as reports of trying any tobacco product for the first time during the last 12-months. Initiation of current use will be measured as reports of tobacco use within the 30 days prior to the survey and having initiated experimental use prior to that 30-day period. The secondary outcome will be tobacco use intention, a consistent predictor of subsequent use in never users [66]. Finally, tobacco use initiation at baseline will be measured by asking ever users about age of initiation.

Table 1 Tobacco point-of-sale audit

Is not located within 100 yards of educational institutions

Presence of signage about the ban on tobacco sales to minors

Presence of two or fewer tobacco advertisements

Tobacco advertisement meets size, content and warning specifications

Tobacco packages have required textual and pictorial warnings

Did not sell tobacco to minors

Did not sell gutkha sales 
Table 2 Public place smoke-free audit

Presence of no smoking signage

Absence of active smoking

Absence of smoking aids, e.g., ashtrays, matchboxes, lighters

Absence of cigarettes butts or bidi ends

Responses by patrons saying they did not observe anyone smoke

Community tobacco environment Data from GIS mapping, Tobacco POS Audits and Public Place Audits will be used to measure the following community factors:

- Tobacco vendor and tobacco advertisement density: Spatial data about tobacco vendors and tobacco advertisements will be used to measure vendor density, proximity and clustering based on prior work $[8,14,15,67,68]$. We will use several measures of spatial distribution including density, clustering (hotspots), and distance [69]. Density will be calculated as the ratio of enumerated features (i.e., vendors) to square meters and to population size in the overall community. We will also calculate location quotients to measures the concentration of tobacco vendors and tobacco advertisements [70]. Clustering will be measured through nearest neighbor analysis [70], spatial autocorrelation using the Global Moran's I statistic [71], and hotspot/cold spot analysis using the Getis-Ord Gi* Statistic [72].

- Community compliance with POS policies and smoke-free policies: For each community, the POS Compliance Score and Smoke-free Compliance Score described above will be averaged across all sampled tobacco vendors to create the Community POS Compliance Score and Community Smoke-free Compliance Score.

Mediators and moderators To identify pathways by which CTE factors are associated with tobacco use, the following partial mediators will be examined: self-reported sources of tobacco, perceived ease of access, exposure to tobacco advertisements, perceived tobacco use norms and self-reported exposure to secondhand smoke. Moderators will include parental tobacco use, parenting style, parental support, household tobacco use policy and household SES.

Potential confounders To address confounding, we will include factors guided by our conceptual framework and the literature $[19,41,73-76]$ about community (SES, distribution of religions, population density), family (parent-child communication about tobacco) and adolescent level factors (religion, age, gender, peer tobacco use, depressiveness).
All data will be stored on secured and passwordprotected computers, and only IRB certified study team members will have access to the data. Personal identifiers will be stored for follow-up data collection. A data quality assurance plan outlines the quality standards and reporting requirements.

\section{Statistical analysis}

We will assess whether CTE factors are associated with adolescent tobacco use initiation, and measure the role of moderators and partial mediators (Fig. 1). Since individuals will be nested within communities, data analysis will be conducted using a multilevel random-effects regression framework [77, 78] using Stata and GLLAMM [79].

Direct associations Model building will be sequential, starting with a model for the outcome including CTE factors then adding family and individual level factors in blocks to examine whether associations hold statistically after inclusion of variables at each level. In addition to Wald tests of the significance of single predictors, likelihood ratio tests will be used to assess the joint significance of sets of related predictors (e.g., multiple vendor density and compliance measures). In longitudinal analyses, we will also estimate growth curves [80] for community level compliance latent classes.

Multilevel moderation analysis will assess whether the family factors are moderators. We will use cross-level analysis to assess moderation by testing interaction terms between level 1 and level 2 variables [81], e.g., between community compliance and family context (shown as arrow d in Fig. 1).

Mediation analysis Mediation (See Fig. 1, see arrows a, b and c) will be assessed in several ways. Statistically significant associations for arrows $\mathrm{a}, \mathrm{b}$ and $\mathrm{c}$ will indicate partial mediation [82, 83]. We will also use structural equation modeling to assess multiple mediators simultaneously [84].

Statistical power Our power calculations account for the clustering of households in the sample design, and assume a range of community intraclass correlations (ICC) of 0.01-0.05 [8]. Based on a $85 \%$ retention, we expect an effective sample size to be between 1199 (design effect of 1.29 or ICC of 0.01) and 631 (design effect of 2.45 or ICC of 0.05 ). Power calculations were performed for two scenarios. First, to assess the effect of community level variables on the individual level variables, the random intercept logistic regression model (each community having a different intercept) with initiation of tobacco use as the outcome variable and a CTE variable at the community level as the primary predictor was used [85]. This analysis showed that we have $>80 \%$ power to 
detect standardized regression coefficients of sizes 0.07 to 0.09 . Second, we conducted the power analysis for detecting the interaction effects between community level variables and individual level covariate (such as family factors) on adolescent level outcomes. Here the detectable (with $80 \%$ power) standardized regression coefficient for the interaction effects ranged between 0.11 and 0.15 [86]. Sample sizes on the order of 600 are adequate to detect small mediational effects with $80 \%$ power [87]. Hence, we expect our sample to provide adequate power for planned analyses.

\section{Discussion}

India is well positioned to address its tobacco use problem because of a strong foundation of existing national, state and local tobacco control policies. Youth are important beneficiaries of these laws because they are susceptible to tobacco access, exposure and marketing [13-17], which are widespread in urban India [8, 2022]. Detailed policy implementation and compliance data from local communities where important tobacco control policies, tobacco products and marketing ultimately interface with community members, including youth, is badly needed. This study will contribute substantially to research on tobacco control policy implementation and the influence of policy compliance on adolescent tobacco use, a behavioral risk factor of immense public health importance in India and globally.

\section{Strengths and limitations}

There are notable strengths and limitations to this study. First, we will obtain a representative sample of communities and adolescents in both cities, which will enhance generalizability to these major Indian cities, and to other urban areas in India and the region. Second, this study will recruit a longitudinal cohort to study adolescent tobacco use initiation and trajectories. An important challenge to validity is attrition, which can typically be $20 \%$ per year in US-based research [88]. We have obtained high retention in prior longitudinal studies in India of $>5.5$ years $[89,90]$. We will obtain contact information of all participants and relatives during Wave 1 to facilitate subsequent data collection.

The findings from this study are expected to be useful in guiding future tobacco control policy enforcement, development and implementation to reduce adolescent tobacco use in India. They can be generalized with some caution to other countries in the region, and perhaps even to communities consisting of recent Indian diaspora.

\section{Abbreviations}

COTPA: Cigarettes and Other Tobacco Products Act; CTE: Community Tobacco Environment; GIS: Geographic Information Systems; GLLAMM: Generalized Linear Latent And Mixed Models; GPS: Global Positioning System; ICC: Intraclass correlation; IV Unit: Investigator Unit; NSSO: National Sample Survey Office; POS: Point-of-sale; WHO: World Health Organization

\section{Acknowledgements}

The authors are thankful to the research team in India (Sameer Narake, Manisha Pathak and Sutapa Biswas) and the USA (Hsing-Fang Hsieh and others) for their hard work and dedication to the project. We are also thankful to all research participants.

\section{Funding}

National Cancer Institute/National Institutes of Health: R01CA201415 (Multiple PIs: Ritesh Mistry (contact), Mangesh S. Pednekar). The funder has no role in the design, implementation and interpretation of study results.

Availability of data and materials

After data collection is completed, de-identified study data, data dictionary and a methodology report will be made available from the corresponding author on reasonable request.

\section{Authors' contributions}

As Multiple PIs, RM and MSP provided scientific leadership in the development of the study. RM drafted the paper and played a major role, with contributions from MSP, in developing the research questions, conceptual framework, design and statistical / spatial analysis plan. MSP conceived of the field sites, developed the field operations plan, and provided critical inputs in all aspects of the study. WM and PCG provided critical inputs in all areas of the study approach. TR developed the sampling plan, conducted the power analysis, critically reviewed the statistical analysis plan and provided critical input on the study concept. SA, NP, KA and MS provided critical inputs in operationalizing the study protocol. All co-authors edited drafts of the paper, and agreed to the content of the submitted version. All authors read and approved the final manuscript.

\section{Ethics approval and consent to participate}

The study is approved by the Institutional Review Boards of the University of Michigan University (HUM00129316) and Healis Sekhsaria Institute for Public Health (2015/18/03). Parental/guardian permission will be obtained for minor participants (under 18 years of age), who will be asked to provide assent prior to enrollment in the study. The ethics committees approved verbal consent instead of written consent by weighing the minimal risk level of the study against the effect of low literacy on equitable recruitment. Any protocol changes will be reported immediately to each Institutional Review Board.

\section{Consent for publication}

Not applicable.

\section{Competing interests}

The authors declare that they have no competing interests.

\section{Publisher's Note}

Springer Nature remains neutral with regard to jurisdictional claims in published maps and institutional affiliations.

\section{Author details}

${ }^{1}$ Department of Health Behavior and Health Education, University of Michigan School of Public Health, 1415 Washington Heights, SPH I, Room 3806, Ann Arbor, MI 48109-2029, USA. ${ }^{2}$ Healis Sekhsaria Institute for Public Health, Navi Mumbai, India. ${ }^{3}$ Department of Biostatistics, University of Michigan, Ann Arbor, USA. ${ }^{4}$ Survey Research Center, Institute for Social Research, University of Michigan, Ann Arbor, USA. ${ }^{5}$ Cancer Foundation of India, Kolkata, India. ${ }^{6}$ Department of Health Policy and Management, University of California, Los Angeles, USA.

Received: 20 March 2018 Accepted: 19 June 2018

Published online: 03 July 2018

\section{References}

1. WHO. Global adult tobacco survey (GATS): India - 2016-17. Geneva: World Health Organization; 2017.

2. WHO. Global Youth Tobacco Survey (GYTS): India - 2009. Geneva: World Health Organization; 2010. 
3. Jha P, Jacob B, Gajalakshmi V, Gupta PC, Dhingra N, Kumar R, Sinha DN, Dikshit RP, Parida DK, Kamadod R, et al. A nationally representative case-control study of smoking and death in India. N Engl J Med. 2008;358(11):1137-47.

4. Sinha D, Palipudi K, Gupta P, Singhal S, Ramasundarahettige C, Jha P, Indrayan A, Asma S, Vendhan G. Smokeless tobacco use: a meta-analysis of risk and attributable mortality estimates for India. Indian J Cancer. 2014;51(5):73.

5. Cummings KM, Hyland A, Perla J, Giovino GA. Is the prevalence of youth smoking affected by efforts to increase retailer compliance with a minors' access law? Nicotine Tob Res. 2003;5(4):465-71.

6. Mistry R, Pimple S, Mishra G, Gupta PC, Pednekar M, Ranz-Schleifer N, Shastri S. Compliance with point-of-sale tobacco control policies in school-adjacent neighborhoods in Mumbai, India. Am J Health Promot. 2015;30(6):433-40.

7. Chaudhry S, Chaudhry S, Chaudhry K. Point of sale tobacco advertisements in India. Indian J Cancer. 2007;44(4):131-6.

8. Mistry R, Pednekar M, Pimple S, Gupta PC, McCarthy WJ, Raute LJ, Patel M, Shastri SS. Banning tobacco sales and advertisements near educational institutions may reduce students' tobacco use risk: evidence from Mumbai, India. Tob Control. 2013;24(e1):e100-7.

9. Elf JL, Modi B, Stillman F, Dave P, Apelberg B. Tobacco sales and marketing within 100 yards of schools in Ahmedabad City, India. Public Health. 2013; 127(5):442-8.

10. Goel S, Ravindra K, Singh RJ, Sharma D. Effective smoke-free policies in achieving a high level of compliance with smoke-free law: experiences from a district of North India. Tob Control. 2014;23(4):291-4.

11. Nair S, Schensul JJ, Bilgi S, Kadam V, D' Mello S, Donta B. Local responses to the Maharashtra gutka and pan masala ban: a report from Mumbai. Indian J Cancer. 2012;49(4):443-7.

12. Pimple S, Gunjal S, Mishra GA, Pednekar MS, Majmudar P, Shastri SS. Compliance to Gutka ban and other provisons of COTPA in Mumbai. Indian J Cancer. 2014;51(Suppl 1):S60-6.

13. Henriksen L, Feighery EC, Schleicher NC, Cowling DW, Kline RS, Fortmann SP. Is adolescent smoking related to the density and proximity of tobacco outlets and retail cigarette advertising near schools? Prev Med. 2008;47(2):210-4.

14. McCarthy WJ, Mistry R, Lu Y, Patel M, Zheng H, Dietsch B. Density of tobacco retailers near schools: effects on tobacco use among students. Am J Public Health. 2009;99(11):2006-13.

15. Novak SP, Reardon SF, Raudenbush SW, Buka SL. Retail tobacco outlet density and youth cigarette smoking: a propensity-modeling approach. Am J Public Health. 2006;96(4):670-6.

16. Pokorny $\mathrm{SB}$, Jason LA, Schoeny ME. The relation of retail tobacco availability to initiation and continued smoking. J Clin Child Adolesc Psychol. 2003;32(2):193-204.

17. Schooler C, Feighery E, Flora JA. Seventh graders' self-reported exposure to cigarette marketing and its relationship to their smoking behavior. Am J Public Health. 1996;86(9):1216-21.

18. Henriksen L, Feighery EC, Wang Y, Fortmann SP. Association of retail tobacco marketing with adolescent smoking. Am J Public Health. 2004;94(12):2081-3.

19. Henriksen L, Schleicher NC, Feighery EC, Fortmann SP. A longitudinal study of exposure to retail cigarette advertising and smoking initiation. Pediatrics. 2010;126(2):232-8

20. Arora M, Reddy KS, Stigler MH, Perry CL. Associations between tobacco marketing and use among urban youth in India. Am J Health Behav. 2008; 32(3):283-94.

21. Bansal R, John S, Ling PM. Cigarette advertising in Mumbai, India: targeting different socioeconomic groups, women, and youth. BMJ. 2005;14(3):201

22. Shah PB, Pednekar MS, Gupta PC, Sinha DN. The relationship between tobacco advertisements and smoking status of youth in India. Asian Pac J Cancer Prev. 2008;9(4):637-42.

23. Henriksen $\mathrm{L}$. The retail environment for tobacco: a barometer of progress towards the endgame. Tob Control. 2015;24(e1):e1-2.

24. Donovan RJ, Jancey J, Jones S. Tobacco point of sale advertising increases positive brand user imagery. BMJ. 2002;11(3):191.

25. Carter OB, Phan T, Mills BW. Impact of a point-of-sale tobacco display ban on smokers' spontaneous purchases: comparisons from postpurchase interviews before and after the ban in Western Australia. Tob Control. 2015; 24(e1):e81-6.

26. John R, Cheney MK, Azad MR. Point-of-sale marketing of tobacco products: taking advantage of the socially disadvantaged? J Health Care Poor Underserved. 2009;20(2):489-506.

27. Wakefield MA, Chaloupka FJ, Kaufman NJ, Orleans CT, Barker DC, Ruel EE. Effect of restrictions on smoking at home, at school, and in public places on teenage smoking: cross sectional study. BMJ. 2000;321(7257):333-7.
28. Lovato CY, Sabiston CM, Hadd V, Nykiforuk Cl, Campbell HS. The impact of school smoking policies and student perceptions of enforcement on school smoking prevalence and location of smoking. Health Educ Res. 2007;22(6): 782-93.

29. Luthar SS, Sawyer JA, Brown PJ. Conceptual issues in studies of resilience: past, present, and future research. Ann N Y Acad Sci. 2006;1094:105-15.

30. Jessor R. Risk behavior in adolescence: a psychosocial framework for understanding and action. J Adolesc Health. 1991;12(8):597-605.

31. Zimmerman MA, Bingenheimer JB, Notaro PC. Natural mentors and adolescent resiliency: a study with urban youth. Am J Community Psychol. 2002;30(2):221-43.

32. Baumrind D. The influence of parenting style on adolescent competence and substance use. J Early Adolesc. 1991;11(1):56.

33. Mistry R, McCarthy W, Yancey A, Lu Y, Patel M. Resilience and patterns of health risk behaviors in California adolescents. Prev Med. 2009:48(3):291-7.

34. Chassin L, Presson CC, Rose J, Sherman SJ, Davis MJ, Gonzalez JL. Parenting style and smoking-specific parenting practices as predictors of adolescent smoking onset. J Pediatr Psychol. 2005;30(4):333

35. Yancey AK, Grant D, Kurosky S, Kravitz-Wirtz N, Mistry R. Role modeling, risk, and resilience in California adolescents. J Adolesc Health. 2011;48(1):36-43.

36. Ray CS, Pednekar MS, Gupta PC, Bansal-Travers M, Quah A, Fong GT. Social impacts on adult use of tobacco: findings from the international tobacco control project India, wave 1 survey. WHO South East Asia J Public Health. 2016;5(2):123-32.

37. Doubeni CA, Li W, Fouayzi H, DiFranza JR. Perceived accessibility of cigarettes among youth: a prospective cohort study. Am J Prev Med. 2009; 36(3):239-42.

38. Hansen WB, Graham JW. Preventing alcohol, marijuana, and cigarette use among adolescents: peer pressure resistance training versus establishing conservative norms. Prev Med. 1991;20(3):414-30.

39. Corbett KK. Susceptibility of youth to tobacco: a social ecological framework for prevention. Respir Physiol. 2001;128(1):103-18.

40. Ennett ST, Foshee VA, Bauman KE, Hussong A, Faris R, Hipp JR, Cai L. A social contextual analysis of youth cigarette smoking development. Nicotine Tob Res. 2010;12(9):950-62.

41. Wilcox P. An ecological approach to understanding youth smoking trajectories: problems and prospects. Addiction. 2003;98(Suppl 1):57-77.

42. Nowlin PR, Colder CR. The role of ethnicity and neighborhood poverty on the relationship between parenting and adolescent cigarette use. Nicotine Tob Res. 2007:9(5):545-56.

43. Cook TD. The case for studying multiple contexts simultaneously. Addiction. 2003;98(Suppl 1):151-5.

44. Duncan JG, Raudenbush SW. Neighborhoods and adolescent development: how can we determine the links. In: Booth A, Crouter JL, editors. Does it take a village? Community effects on children, adolescents and families edn. Pennsyvania: State College University Press; 2001. p. 105-36.

45. Stokols D. Translating social ecological theory into guidelines for community health promotion. Am J Health Promot. 1996;10(4):282-98.

46. Bandura A. Human agency in social cognitive theory. Am Psychol. 1989; 44(9):1175-84

47. Flay B, Petraitis J. The theory of triadic influences: a new theory of health behavior with implication for preventive interventions. In: Albrecht GS, editor. Advances in medical sociology, vol IV: a reconsideration of models of health behavior change. Greenwich: JAI Press; 1994.

48. Compas BE, Hinden BR, Gerhardt CA. Adolescent development: pathways and processes of risk and resilience. Annu Rev Psychol. 1995;46:265-93.

49. NSSO. Urban frame survey. In: Ministry of statistics and programme implementation; 2017

50. Gupta PC, Ray CS. Tobacco and youth in the South East Asian region. Indian J Cancer. 2002;39(1):5-34.

51. McCarthy WJ, An N, Hanson TL, Zheng H, Dietsch B, Rohrbach L. How school-level ethnic composition and parent education affect teen smoking. In: Biennial investigators' meeting of the California Tobacco-Related Disease Research Program. University of California, Office of the President. Sacramento; 2007

52. Pednekar MS, Gupta PC. Tobacco use among school students in Goa, India. Indian J Public Health. 2004;48(3):147-52.

53. Project I. TCP India wave 2 (2012-2013) technical report. Navi Mumbai: University of Waterloo, Waterloo and Healis-Sekhsaria Institute for Public Health; 2016.

54. WHO: Global adult tobacco survey (GATS): India - 2009-2010. 2011. 
55. Vardavas Cl, Connolly GN, Kafatos AG. Geographical information systems as a tool for monitoring tobacco industry advertising. Tob Control. 2009;18(3):190-6.

56. Frank LD, Saelens BE, Chapman J, Sallis JF, Kerr J, Glanz K, Couch SC, Learnihan V, Zhou C, Colburn T, et al. Objective assessment of obesogenic environments in youth: geographic information system methods and spatial findings from the neighborhood impact on kids study. Am J Prev Med. 2012;42(5):e47-55

57. Lee JG, Henriksen L, Myers AE, Dauphinee AL, Ribisl KM. A systematic review of store audit methods for assessing tobacco marketing and products at the point of sale. Tob Control. 2014;23(2):98-106.

58. Lee JG, Gregory KR, Baker HM, Ranney LM, Goldstein AO. "May I buy a pack of marlboros, please?" A systematic review of evidence to improve the validity and impact of youth undercover buy inspections. PLoS One. 2016; 11(4):e0153152.

59. DiFranza JR, Celebucki CC, Mowery PD. Measuring statewide merchant compliance with tobacco minimum age laws: the Massachusetts experience. Am J Public Health. 2001;91(7):1124-5.

60. Difranza JR, Savageau JA, Bouchard J. Is the standard compliance check protocol a valid measure of the accessibility of tobacco to underage smokers? Tob Control. 2001;10(3):227-32.

61. The Union. Assessing compliance with smoke-free laws: a "how-to" guide for conducting compliance. 2nd ed; 2014. p. 1-34.

62. Goel S, Kumar R, Lal P, Sharma D, Singh R. Refining compliance surveys to measure the smokefree status of jurisdictions using the Delphi method. Public Health Action. 2013;3(4):342-5.

63. Kumar R, Chauhan G, Satyanarayana S, Lal P, Singh RJ, Wilson NC. Assessing compliance to smoke-free legislation: results of a sub-national survey in Himachal Pradesh, India. WHO South-East Asia Journal of Public Health. 2013;2(1):52.

64. Flay BR, Hu FB, Siddiqui O, Day LE, Hedeker D, Petraitis J, Richardson J, Sussman S. Differential influence of parental smoking and friends' smoking on adolescent initiation and escalation of smoking. J Health Soc Behav. 1994;35(3):248-65.

65. O'Loughlin J, Karp I, Koulis T, Paradis G, Difranza J. Determinants of first puff and daily cigarette smoking in adolescents. Am J Epidemiol. 2009;170(5):585-97.

66. Chassin L, Presson C, Sherman S, Montello D, McGrew J. Changes in peer and parent influence during adolescence: longitudinal versus cross-sectional perspectives on smoking initiation. Dev Psychol. 1986;22(3):327-34.

67. Chuang YC, Cubbin C, Ahn D, Winkleby MA. Effects of neighbourhood socioeconomic status and convenience store concentration on individual level smoking. J Epidemiol Community Health. 2005;59(7):568-73.

68. Leatherdale ST, Cameron R, Brown KS, McDonald PW. Senior student smoking at school, student characteristics, and smoking onset among junior students: a multilevel analysis. Prev Med. 2005;40(6):853-9.

69. Mitchell A. The ESRI quide to GIS analysis, vol. 2. Redlands: ESRI Press; 2005.

70. Ebdon D. Statistics in Geography. 2nd ed. Malden: Blackwell Publishing; 1985

71. Moran P. Notes on continuous stochastic phenomena. Biometrika. 1950; $37(1): 17-23$

72. Getis A, Ord K. The analysis of spatial association by use of distance statistics. Geogr Anal. 1992;24:189-206.

73. Brown SL, Rinelli LN. Family structure, family processes, and adolescent smoking and drinking. J Res Adolesc. 2010;20(2):259-73.

74. Hoffmann JP. Family structure, community context, and adolescent problem behaviors. J Youth Adolesc. 2006;35:867-80.

75. Lovato CY, Zeisser C, Campbell HS, Watts AW, Halpin P, Thompson M, Eyles J, Adlaf E, Brown KS. Adolescent smoking: effect of school and community characteristics. Am J Prev Med. 2010;39(6):507-14.

76. Tyas SL, Pederson LL. Psychosocial factors related to adolescent smoking: a critical review of the literature. Tob Control. 1998;7(4):409-20.

77. McCulloch CE, Searle SR. Generalized, linear and mixed models. New York: John Wiley and Sons; 2001

78. Hedeker D, Gibbons R. Longitudinal data analysis. New York: John Wiley and Sons; 2006.

79. StataCorp. Stata Statistical Software: Release 15. College Station: StataCorp LLC; 2017.

80. McArdle JJ, Epstein D. Latent growth curves within developmental structural equation models. Child Dev. 1987;58(1):110-33.

81. Raudenbush SW, Bryk AS. Hierarchical linear models: applications and data analysis methods. Thousand Oaks: Sage Publications Inc.; 2002.

82. Krull JL, MacKinnon DP. Multilevel mediation modeling in group-based intervention studies. Eval Rev. 1999;23(4):418-44.
83. Krull JL, MacKinnon DP. Multilevel modeling of individual and group level mediated effects. Multivariate Behav Res. 2001;36(2):249-77.

84. Little TD. Longitudinal structural equation modeling. New York: Guilford Press; 2013.

85. Snijder T. Power and sample size in multilevel linear models. In: Everitt BS, Howell DC, editors. Encyclopedia of statistics in behavioral sciences, vol. 3. New York: Wiley; 2005. p. 1570-3.

86. Spybrook J, Raudenbush SW, Congdon R, Martinez A. Optimal design for longitudinal and multilevel research. 2009.

87. Fritz MS, Mackinnon DP. Required sample size to detect the mediated effect. Psychol Sci. 2007;18(3):233-9.

88. Joffe A, McNeely C, Colantuoni E, An MW, Wang W, Scharfstein D. Evaluation of school-based smoking-cessation interventions for selfdescribed adolescent smokers. Pediatrics. 2009;124(2):e187-94.

89. Gupta PC, Pednekar MS, Parkin DM, Sankaranarayanan R. Tobacco associated mortality in Mumbai (Bombay) India. Results of the Bombay cohort study. Int J Epidemiol. 2005;34(6):1395-402.

90. Pednekar MS, Gupta PC, Yeole BB, Hebert JR. Association of tobacco habits, including bidi smoking, with overall and site-specific cancer incidence: results from the Mumbai cohort study. Cancer Causes Control. 2011;22(6): 859-68.

\section{Ready to submit your research? Choose BMC and benefit from:}

- fast, convenient online submission

- thorough peer review by experienced researchers in your field

- rapid publication on acceptance

- support for research data, including large and complex data types

- gold Open Access which fosters wider collaboration and increased citations

- maximum visibility for your research: over $100 \mathrm{M}$ website views per year

At BMC, research is always in progress.

Learn more biomedcentral.com/submissions 